\title{
SCALING IMPACT IN THE HEALTH SECTOR
}

\author{
A.L. HAMMOND \\ Ashoka \\ Arlington, Virginia, U.S.A. \\ al.hammond@gmail.com
}

\begin{abstract}
This essay examines possible routes to achieving significant health improvements in the underserved populations of developing countries. It argues that unconventional strategies, largely outside the health sector as conventionally defined, have the greatest potential to scale sustainably. The essay describes two such strategies - nutrition and safe drinking water. In particular, the essay argues that impact investors focused on social enterprises can best maximize their health impact by looking closely at the strategies described herein.
\end{abstract}

Health is one of the areas that have been traditionally left to the public sector and to charity or donor funding, largely via NGOs. As a consequence, there has been relatively less private sector investment in base of the pyramid (BoP) health ventures compared to microfinance or off-grid energy, despite the fact that many social entrepreneurs work in the health sector. But that situation is beginning to change as for-profit clinic networks try their wings, start-ups offer new diagnostic tools intended for the BoP, and the potential of mobile phones and tablets to empower both front-line health workers and patients begins to be tapped. These activities have very significant potential and deserve the attention of impact investors.

All of these entrepreneurial efforts, however, are still small. Most large-scale health interventions are expensive. Internationally-funded pilots or narrowly focused and traditional efforts such as vaccination campaigns or HIV/AIDs treatment programs require massive external funding. In contrast, the unmet needs are enormous-for 3-4 billion people in especially rural and many peri-urban communities in develop- 
ing countries, there is very limited access to generally poor quality care. It is not obvious how we get to meaningfully impact on those needs from where we are now. Moreover, it is pertinent that, historically, most major innovations in public health have come from outside the medical domain or even outside what was at the time considered to be the proper concerns of public health. Two major examples of such innovations are the introduction of centralized urban water and sanitation early in the $20^{\text {th }}$ century, and the rise of the environmental movement and its concern with toxic substances in air, water, and food in the second half of that century. It thus seems reasonable to ask whether BoP health care might equally benefit from some orthogonal approaches.

My colleagues and I at Ashoka have been following this line of reasoning for the last couple of years, drawing on the wisdom and experimentation of the 600-some Ashoka Fellows who work in health. We have found it useful to not just think about health interventions, but rather to consider what contributes to a peoples' wellness and vitality, to their ability to succeed in life. Our tentative conclusions have focused on two complementary but different system-level interventions that seem critical to scaling beneficial health impacts. One of these interventions addresses the relation between the agriculture/food ecosystem and human nutrition, while the other focuses on safe water and its relation to human health. Both are largely neglected by healthcare systems and international health programs.

\section{THE AGRICULTURE/FOOD ECOSYSTEM AND HUMAN NUTRITION}

One of the levers for scale comes from the unintended consequences of what we might call the agriculture/food ecosystem. Modern farming systems, it turns out, produce higher yields but less nutritious raw materials as measured by the micronutrient content of grains, vegetables, and fruits. This high yield, low nutrient situation is also true for the meat from animals that are fed those grains. To compound the problem, modern food processing approaches often find it efficient to remove much of the remaining micronutrients in order to achieve longer shelf life or consistency of product, among other similar reasons. Food companies sometimes add back micronutrients to "fortify" the final product, but these added components are likely to be in an inexpensive form that is not well-absorbed, or easily used, by the human body. Heavily-advertised fast foods and high-sugar beverages in the developed world and diets in the BoP that are often restricted to a few subsidized staples intensify the prevalence of "empty" calories in the world's food supply. The net result 
is that some 2 billion people worldwide are malnourished in the sense that they suffer micronutrient deficiencies. At the same time, others are over-nourished in the sense that they consume calories in excess of their needs and become part of the growing epidemic of obesity in rich and poor countries alike (Muller \& Krawinkel, 2005; Hammond \& Dube, 2012). These nutritional problems turn out to be closely connected.

Nutrition matters-indeed, we are what we eat to a significant degree. Many of the enzyme systems in the human body depend upon trace minerals, and so deficiencies of iron, zinc, selenium, manganese, and other micronutrients (essential minerals, vitamins, and fatty acids) can impair health and wellness. Moreover, the chemical form of these micronutrients in our food supply or in nutritional supplements makes a huge difference. Iron in human breast milk, for example, is in a complex, protected form that is highly bioavailable to the infant. On the other hand, iron in an elemental form, often used in baby formula or nutritional supplements, is not easily absorbed and used by the body and is also readily available to any bacterial infection present in the child (bacteria need iron to grow as well, and can outcompete an infant for it). Because of regulatory failures, consumers have essentially no useful information about the micronutrient content of the food they buy since food labels (and even those on vitamin and mineral supplements) say nothing about the form (and thus the bioavailability) of the micronutrients in a product.

Nutrition plays an especially important role in the womb and in the young infant, and can in fact influence one's entire lifetime course of wellness and illness. It is now known that the fetal environment in a malnourished womb triggers epigenetic signals that turn specific genes on or off in ways that prepare the child for an "expected" lifetime of food scarcity. The child is born with extra fat cells, among other differences, and yet is at risk of premature birth and/or low birth weight. This dynamic is a survival mechanism that has helped our species overcome highly variable environmental conditions before the advent of agriculture about 10,000 years ago. But it also causes life-long, geneticallydriven predispositions to obesity, diabetes, and cardiovascular disease, as well as stunting and impairing cognitive development in severe cases. Nearly $50 \%$ of children in India are stunted by age 2 , and the figures for Sub-Saharan Africa, while lower, are rising. The cognitive deficits affect ability to plan, impulse control, and other executive functions that are important to success in school and in employment. Low birth-weight infants are also much more likely to die from infectious disease and other causes in their first 5 years of life. The bottom line is that poor nutrition for teenage girls and pregnant women can significantly pre-determine the course of a country's public health burdens which are increasingly 
dominated by chronic illnesses such as diabetes and cardiovascular disease. Such poor nutrition also creates very challenging barriers to a country's ambitions for competitive success in a rapidly changing global economy as a large fraction of the population becomes cognitively incapable of participation in high-skilled work and civil society.

Getting maternal and infant nutrition right is a significant lever, and the costs are not especially high-even if governments heavily subsidize the right kind of nutrient-rich food for this relatively small segment of their population. The challenges are more in distribution and effective management (the UN Millennium Challenge goals for maternal health lag furthest behind the other Millennium goals) and in warding off other concerns that might mitigate the impact of a "nutrition security" public health strategy. But at present, nutrition is hardly even visible as a health care priority on national and international agendas.

\section{SAFE DRINKING WATER AS A CRITICAL COMPONENT OF HEALTH}

Our research suggests that a second critical leverage point for scaling health impact is access to safe drinking water. The relationship between safe drinking water and human health is quite straightforward. The high incidence of water borne disease and of other health impacts from dissolved solids or chemical contaminants in untreated water supplies (such as arsenic, high fluoride or calcium levels, pesticide residues) is well known, as are methods of treating water to remove biological and chemical contaminants.

But doing something about the problem falls outside the scope of health programs at both national and international levels-it's somebody else's problem, and yet prevention of the health burdens of unsafe water is much less expensive-for consumers and national governmentcompared to treatment. Not only is frequent water-borne illness and the associated diarrhea in infants and young children a major cause of death, it also exacerbates malnutrition. Frequent diarrhea can also significantly undercut the effectiveness of childhood vaccinations, rendering the child vulnerable to easily-avoided illnesses-and, in effect, wasting much of the cost and effort of vaccination programs. Pesticide residues in water and food in areas with intensive agriculture are also closely associated with increases in cancer.

However, what is particularly interesting about safe drinking water as a leverage point for achieving health impact is its potential as a sustain- 
able distribution model for water, nutrition, and other health services. Previous work has indicated that the sweet spot for impact in the near term is likely to come not from centralized urban water systems, nor from point-of-use (household) water treatment, but from communityscale strategies (Koch \& Hammond, 2009). These strategies typically involve community-scale utilities, treating locally-available raw water and selling it to households from a centralized location, and in some cases, distributing the product to the doorstep. In India, which has had perhaps the greatest experience with such models, it is possible to supply a household's safe drinking and cooking water for an annual cost of between $\$ 20$ and $\$ 40$, and to do so on a continuing basis with reasonable penetration of households, especially at the lower prices. Since the estimated annual costs of treating water-borne disease exceed $\$ 50$ per household (Jain, 2012), there is a direct and immediate consumer financial benefit quite apart from avoiding loss of work and school days. Additional public health benefits, such as reduced infant malnutrition and death, reduced chronic disease decades later, more effective vaccination outcomes, etc., come at no cost.

The water treatment centers in these models become central to the life of communities, especially since people come every day to pick up their water. It is thus not hard to envision the centers as distribution points for nutrition-rich food or nutritional supplements. Likewise, the social marketing required to induce potential customers to pay for clean water lays a foundation and a marketing infrastructure for educating them about the benefits of improved nutrition for mothers-to-be and young children. At least one of the Indian water companies, a close Ashoka partner, is already experimenting with vaccination "camps" on pre-arranged and advertised days at water treatment centers. If such models scale, and there is evidence that they can, there is scope for replication in many countries. Such an orthogonal approach, largely outside traditional healthcare models and focused instead on wellness, has the potential to achieve significant impact. Historically, it would not be the first time.

Consider this essay, then, a call to action to tear down the artificial walls that now separate healthcare, nutrition and food quality concerns, and safe drinking water. Let us accept that wellness is the goal of all three areas, and optimize public and international funds for maximum impact. Equally, for impact investors that care about real impact, please seek out ways with your investment dollars to encourage such integration. I argue that safe drinking water may be the most scalable wellness intervention now available, as well as a distribution vehicle for other wellness services. Please do your own analysis and let it guide your investment decisions for the health sector. 


\section{REFERENCES}

Hammond, R., \& Dube, L. 2012. A system science perspective and transdisciplinary models for food and nutrition security. PNAS, July 23.

Jain, A. 2012. Personal communication. CEO, Healthpoint Services India Pvt. Ltd. Koch, J., \& Hammond, A. 2009. The need for safe water as a market opportunity.

Innovations, Summer 2009: 107-117.

Muller, O., \& Krawinkel, M. 2005. Malnutrition and health in developing countries.

CMAJ, 173: 279-286.

Dr. Hammond is a member of the Leadership Group and director of the Health for All program at Ashoka. He is also co-founder of Healthpoint Services, a social enterprise providing safe drinking water and health services in rural India. He previously worked at the World Resources Institute and the American Association for the Advancement of Science, and has led six entrepreneurial startup enterprises over the course of his career. Dr. Hammond worked closely with Professor CK Prahalad to found the Base of the Pyramid movement and has published widely in the scientific and policy literature. He received a BS in engineering (with honors) in social science from Stanford, and a PhD in applied mathematics from Harvard. 


\title{
THE ROLE OF HUMAN CAPITAL IN SCALING SOCIAL ENTREPRENEURSHIP
}

\section{DAWN HARRIS}

Loyola University Chicago

Chicago, Illinois, U.S.A.

dharri1@luc.edu

\author{
YASEMIN KOR \\ University of South Carolina \\ Columbia, South Carolina, U.S.A. \\ ykor@moore.sc.edu
}

\begin{abstract}
In this article, we discuss the importance of human assets in growing and scaling a social venture in order to achieve its objectives and attain financial sustainability. We focus on the three key dimensions of how a social enterprise's human assets contribute to the effectiveness of the company's operations and its missions: 1) human capital acquisition, 2) human capital development, and 3) human capital retention. In discussing and unpacking these three dimensions, we draw from rich insights and reallife examples from two social ventures we studied: Solar Sister of Uganda and E-Health Point of India. These inductively-generated research insights underscore the importance of productive engagement of human assets for the long-term viability of social ventures and in achieving their objectives on a broader social scale.
\end{abstract}

Acknowledgements. We are grateful to Katherine Lucey of Solar Sister and Amit Jain of E-Health Point for sharing their experiences and providing us 
with rich insights and examples for our study. We also thank Thane Kreiner, the Executive Director of the Center for Science, Technology, and Society at Santa Clara University, for providing us with access to the social ventures affiliated with the Center.

\section{INTRODUCTION}

A recent review of the literature suggests that social entrepreneurship research is receiving increased interest and momentum (Short, Moss, \& Lumpkin, 2009). Although a unified definition of social entrepreneurship has not yet emerged (Christie \& Honig, 2006; Weerawardena and Mort, 2006), we use the broad definition of social entrepreneurship that has been developed by Mair and Marti (2006: 37) who view "social entrepreneurship as a process of creating value by combining resources in new ways ... [where] these resource combinations are intended primarily to explore and exploit opportunities to create social value by stimulating social change or meeting social needs." In particular, we focus on the knowledge, skills, and experiences of human resources that are considered among the key contributors to a firm's bundle of resources and capabilities (Hitt, Bierman, Shimizu, \& Kochhar, 2001; Lado \& Wilson, 1994).

In this article, we discuss the importance of human assets in growing and scaling a social venture in order to achieve its objectives and attain financial sustainability. We focus on the three key dimensions of how a social enterprise's human assets contribute to the effectiveness of the company's operations and its missions through (1) human capital acquisition, (2) human capital development, and (3) human capital retention. In the next section of the article, we first explain why human assets matter to social entrepreneurship. We then discuss how a firm's policies and actions in these three key dimensions can promote (or hinder) the growth of the firm which is vitally linked to the delivery of social, environmental, and economic benefits to the impacted communities and stakeholders. In discussing and unpacking these three dimensions, we draw from rich insights and real-life examples from two social ventures we studied, Solar Sister of Uganda and E-Health Point of India. These inductively-generated research insights underscore the importance of productive engagement of human assets for the long-term viability and successful scaling (growth) of social enterprises.

\section{WHY DO HUMAN ASSETS MATTER IN SOCIAL ENTREPRENEURSHIP?}


Systems, activities, and routines for acquiring, organizing, developing, and rewarding human resources directly influence the processes in which firm competencies are developed and renewed (Huselid, 1995; Lado \& Wilson, 1994; Prescott \& Visscher, 1980). These firm-level capabilities which are built on specific human capital development systems can be difficult to imitate because these systems involve routines that are firm-specific, socially complex, and path-dependent (Kor \& Leblebici, 2005; Reed \& DeFillippi, 1990).

With regard, therefore, to the utmost importance of human assets in terms of skills, experience, and good work ethic, social enterprises resemble for-profit corporations. In social ventures, however, the versatility of human resources both at managerial and operational levels often goes beyond the norms we observe in for-profit organizations. Because social ventures usually operate under resource scarcities and in environments with weak institutions (e.g., physical, technological, legal, economic, and educational infrastructures), their human resources often demonstrate increased flexibility, rapid knowledge and skill acquisition, creativity, entrepreneurial drive and energy, and strong intrinsic motivation (Miller, Grimes, McMullen, \& Vogus, 2012). The availability and continuity of managers and operational staff with such qualities matter immensely, therefore, to the development and sustainable growth of a viable social enterprise. Healthy growth brings economies of scale and efficiency in operations, helps build reputation and rapport with targeted communities, and can be a precursor to financial sustainability. However, social ventures often experience heightened challenges in building and growing their human asset stocks and competencies on a par with their expanding operations; thus, overcoming these challenges will be vital to their survival and mission. We turn to such challenges in the next section.

\section{Human Capital Acquisition Challenges and Strategies}

Human capital acquisition involves recruitment of managerial, field/ operational, and support staff with essential knowledge, skills, and mindsets (Adner \& Helfat, 2003). Regarding human capital, Becker's (1975) research distinguishes between generic and specialized human capital. Generic human capital reflects education, skills, and experience that have applicability in multiple firm and industry settings. Specialized human capital tends to be context-specific, such as the knowledge, skills, and connections one can build while working in a specific firm or industry context (e.g., health care industry). Firm-specific human capital, which entails a deep understanding of a particular firm's unique culture, strengths, vulnerabilities and tacit knowledge, is associated with the firm's social context (Castanias \& Helfat, 1991). Firm-specific human 
capital may accumulate through years of experiential learning in company operations where highly specialized skills are developed.

Acquisition of essential human capital could be a major challenge for social ventures due to internal resource shortages and external labor market conditions. In the social ventures we studied (Solar Sister and EHealth Point), we expected to see heightened difficulty in finding and recruiting talent considering the developing nature of the countries where they operated. Surprisingly, however, both firms were satisfied with the pool of talent in these countries (Uganda and India, respectively) and they were able to hire bright, well-educated managers and employees. The key difficulty they experienced had more to do with specialized human capital-many of the hires, while well-educated, lacked contextspecific (specialized) skills.

Specifically, E-Health Point ${ }^{1}$ provides clean water and health care services to low-income rural communities in India. The firm uses information technology to connect local patients with doctors who are at off-site locations. E-Health Point was able to locally recruit well-educated nurses, paramedics, and pharmacists, but as company CEO Amit Jain realized, these employees still needed specialized training in customer management, English speaking proficiency, and the ability to work with computers, all of which are essential to the firm's business model.

As a company objective, Solar Sister ${ }^{2}$ aims to empower women with economic opportunities in Sub-Saharan Africa (mostly Uganda) by recruiting and training them to sell micro solar products in their communities. Through founder Katherine Lucey's social networks and via formal recruitment, Solar Sister was able to hire highly talented managers and regional coordinators. Lucey, however, found out that additional formal training and high touch mentoring/coaching were needed for the employees to become skillful salespeople in the local cultural context, one where entrepreneurship is not always naturally embraced. Thus, for both Solar Sister and E-Health Point, good recruitment was crucial, but it was only the starting point to be supplemented by significant internal development efforts. As such, we now turn to the challenges and strategies of internal human capital development.

\section{Human Capital Development Challenges and Strategies}

${ }^{1}$ http://ehealthpoint.com/

2http://www.solarsister.org/ 
Human capital development involves training as well as motivating and rewarding employees. Human capital pertains to innate and learned abilities, as well as expertise and knowledge gained through education, training, and on-the-job experience (Becker, 1975). Human capital researchers have studied productivity-enhancing investments such as education, health care, training, and firm-specific knowledge acquisitions, as well as the payoff from such investments (Harris \& Helfat, 1997; Gimeno, Folta, Cooper, \& Woo, 1997). This line of research shows that individuals with higher quality human capital deliver better performance, and thus can be key sources of competitive advantage for the firm (Hitt et al., 2001).

In social ventures, managers face the challenge of developing specialized training materials that fit unique service needs, distributing and effectively utilizing these materials in geographical locations that can be dispersed and diverse, and recruiting the appropriate individuals who can do effective training, as well as those who can enhance their skill sets from this training. We anticipated that formal training would be a major component of the systematic training process; however, we did not foresee how important informal training and coaching in social entrepreneurship is. Partly due to the specialized nature of training (i.e., guidance and advice tailored to situations, locations, and individuals) and due to the intimate, personal nature of social interactions, formal training does not suffice. Entrepreneurs (and their managerial/training staff) often need to put in substantial time mentoring and coaching as situations and challenges arise. Formal and informal training thus play complementary yet distinct roles in human capital development.

We also noted that due to differences in interests, values, and a base level of knowledge and skills, not all individuals benefit sufficiently from training. The social venture can end up wasting precious time and resources if training is not properly targeted. Pilot training thus became essential in order to determine the characteristics or competency-value profiles of individual actors (e.g., trainers, sales people, and even managers) who should be targeted for additional formal and informal training.

Solar Sister, for one, continues to try to be more systematic in its training efforts, which are important as the company continues to grow within Uganda and into other countries. The women entrepreneurs whom the company relies on have deep social networks but they do not always realize how to reach those networks. Social entrepreneurs at the company thus undergo formal training and a certification process on how to be successful salespeople. During the training process, they are taught to visualize their social network by drawing a map. Each social entrepreneur can then expand her market and achieve higher sales goals. 
However, while formal training is crucial, a good portion of the critical training is verbal and informal. High touch mentoring and coaching remain essential because experiential learning matters in this context. Katherine Lucey, the founder of Solar Sister, is dedicated to the mentoring of the firm's sales managers (regional coordinators), so she communicates regularly with them to hear their concerns and challenges, offer guidance, and engage in problem solving with them. Sales managers also interact with one another, discussing the challenges encountered and solutions found, and they gain considerably from such lateral learning. In addition, Solar Sister invests in the most promising social entrepreneurs with additional financing and training. These promising social entrepreneurs, called "anchors," have the potential to sell a broader portfolio of products (e.g., solar cell phone chargers) in addition to the primary product, a solar lamp.

Furthermore, the participants in social entrepreneurship (e.g., managers, employees, and community participants) can be motivated and rewarded to increase their engagement and the overall productivity of the organization. However, similar to what we learned about training, we found out that motivation and reward systems are not universal. The specific cultures and social contexts determine how individuals preferred to be motivated and rewarded for higher performance. For instance, Solar Sister encountered a cultural challenge when they tried to motivate and reward high productivity. Unlike the success-oriented culture of the United States, where employees expect to receive monetary rewards for high performance (e.g., bonuses), the culture in Uganda is communityminded, and employees are not accustomed to pay-for-performance incentives. For example, when Solar Sister offered a team leader a bonus system based on her team's sales productivity, the team leader was concerned that this system would create distrust in her team and network. Solar Sister thus turned to an alternative reward mechanism, i.e., a fixed bonus amount that was not directly tied to her productivity. Another example is when some of the Ugandan women entrepreneurs stopped selling solar lamps after they reached the amount of money they needed for health care or their children's school fees.

We thus observe that human capital development policies, including training, motivating and rewarding social entrepreneurs, require culturally-sensitive and creative solutions designed for specific contexts. Such policies benefit from combining formal and informal training efforts. They also benefit from creating a fit between the levels (and types) of investments and the competency-value profiles of individual participants in the social enterprise system. Given all this, we now focus 
on the challenge of how to retain essential human resources after a social venture invests heavily in developing their general and specialized knowledge and skills.

\section{Human Capital Retention Challenges and Strategies}

Unwanted turnover of human resources both at managerial and operational levels can be a serious challenge (Shaw, Duffy, Johnson, \& Lockhart, 2005). In social ventures, turnover can be particularly devastating when firms are in the process of becoming established and trying to scale up. It can be disruptive to day-to-day operations, and is also costly especially when it involves the departure of employees who have received specialized training in the company. High turnover can also be a serious threat to the ability of a firm to scale up in order not only to fulfill its mission (in a larger community) but also to achieve operational and distribution efficiencies that can be paramount to financial viability.

In environments with a scarcity of highly-skilled workers, retention can be hard to achieve. In social enterprises that operate in such environments, we observe that firms face a turnover paradox such that the more they invest in training and developing the specialized human capital of their employees, the more attractive their employees become to their direct competitors or other firms. Put differently, effectiveness in training and human capital development can ironically result in elevated levels of unwanted turnover.

E-Health Point faces this challenge at various levels of employees and management. In the clinics they operate, their technical personnel (nurses and pharmacists) have been heavily recruited by competitor clinics which value E-Health Point employees' customer management and computer skills. As a solution, the company began providing additional incentives and promoting promising employees to supervisor positions. The CEO of the company, Amit Jain, explains that about 30\% of clinic employees are women for whom employment opportunities are usually limited. These employees are treated well at E-Health Point, and they appreciate the supportive company culture and being able to work close to where they live (in rural locations). Combined with incentives and promotion opportunities, these intangibles may act as strong inducements for women to stay with the firm.

Turnover at the middle-management level has also been a challenge for E-Health Point. This level consists of management trainees with MBA degrees who are expected to advance quickly and take on high-level responsibilities. Many of these trainees, however, leave the firm within a 
year because even after a short period of experience at E-Health Point, they become more attractive in the labor market and can get jobs in urban areas. These employees seem to treat the firm as a training ground, and this has been a concern to the company. As a remedy, E-Health Point decided to rely less on generic MBAs and started recruiting sectoral health-care MBAs with specialized skills and a strong interest in health care careers. The company has also recently started experimenting with a two-year contract that discourages employees from leaving early in their tenure.

The E-Health Point example highlights the importance of recruiting the right people with the "right credentials and values." The generic MBAs may not have the best fit for a social venture if their immediate (and near future) goals are to seek high-paying, urban corporate jobs. In social ventures, an important aspect of recruitment is to hire people not only with the appropriate skill set but also with the relevant values, interests, and life style preferences. Social venture jobs tend to have idiosyncratic challenges that many otherwise capable job candidates may fail to cope with (e.g., working in rural and remote areas with resource scarcities and lack of infrastructure). Thus, employee mindset, values, and preferences are just as important as education and experience credentials. In fact, values and mindset are hard to change whereas certain skills can be developed or enhanced through experience and training (Mintzberg, 2009). We thus observe that success in employee retention is intertwined with careful planning and due diligence in the recruitment stage.

It is also noteworthy that offering market-competitive salaries is not always a solution to turnover challenges (as E-Health Point found out). It is critical that employees (including management) in social ventures are compassionate and psychologically invested in the company and its cause (Miller et al., 2012). Employees are entitled to a good pay and work environment, but they also need to be intrinsically motivated, and derive energy and satisfaction from being part of a social enterprise. Put differently, a combination of monetary and non-monetary incentives is likely to be more effective than one form of incentives alone, yet such combinations would only work to the extent they are valued by the employees. Thus, a match is needed in terms of company goals and employee (personal) objectives. This brings us to full circle in terms of the importance of the diligent recruitment strategy as our starting point. Here we emphasize that a successful recruitment strategy involves frank and clear communication of the firm's objectives, challenges, and available resources, as well as the opportunities for personal growth for the employees. Social ventures are dynamic and evolve quickly; thus, these 
conversations need to be revisited regularly. Founders and managers, moreover, play the most central role in this continuum of exchange, education, and co-learning.

\section{CONCLUSION}

In this article, we have focused on how a social enterprise's human assets contribute to company effectiveness and growth through its policies on (1) human capital acquisition, (2) human capital development, and (3) human capital retention. We emphasize that, in recruiting social venture employees, it is important to consider not only generic skills and education, but also the more crucial and harder to find specialized skills necessary for a specific social enterprise. It is also essential that informal training be promoted (although formal training is still important) and that top performers be identified/targeted for additional training. We also note that effective motivation building and rewarding involves designing (monetary and non-monetary) incentives based on specific contexts (e.g., business type, firm and country culture). We highlight that incentives matter a lot in both motivating and retaining social venture employees, but this alone is insufficient. Retention of trained human resources also relies on diligence in the recruitment stage, with equal emphasis placed on both the skill sets appropriate for, and the values relevant to, being part of a social endeavor. In combination, these human capital strategies (in acquisition, development, and retention of human resources) can play a substantial role in the ability of social ventures to achieve viability, prosper, and fulfill their objectives on a broader social scale.

\section{REFERENCES}

Adner, R., \& Helfat, C.E. 2003. Corporate effects and dynamic managerial capabilities.

Strategic Management Journal, October Special Issue 24: 1011-1025.

Becker, G. 1975. Human capital. New York: Columbia University Press.

Castanias, R.P., \& Helfat, C.E. 1991. Managerial resources and rents. Journal of

Management, 17(1): 155-171.

Christie, M., \& Honig, B. 2006. Social entrepreneurship: new research findings. Journal of World Business, 41(1): 1-5.

Gimeno, J., Folta, T.B., Cooper, A.C., \& Woo, C.Y. 1997. Survival of the fittest? Entrepreneurial human capital and the persistence of underperforming firms.

Administrative Science Quarterly, 42: 750-783.

Harris, D., \& Helfat, C.E. 1997. Specificity of CEO human capital and compensation.

Strategic Management Journal, 18(11): 895-920. 
Hitt, M.A., Bierman, L., Shimizu, K., \& Kochhar, R. 2001. Direct and moderating effects of human capital on strategy and performance in professional service firms: a resource-based perspective. Academy of Management Journal, 44(1): 13-28.

Huselid, M.A. 1995. The impact of human resource management practices on turnover, productivity, and corporate financial performance. Academy of Management Journal, 38(3): 635-672.

Kor, Y.Y., \& Leblebici, H. 2005. How do interdependencies among human-capital deployment, development, and diversification strategies affect firms' financial performance? Strategic Management Journal, 26(10): 967-985.

Lado, A.A., \& Wilson, M.C. 1994. Human resource systems and sustained competitive advantage: a competency based perspective. Academy of Management Review, 19(4): 699-727.

Mair, J., \& Marti, I. 2006. Social entrepreneurship research: a source of explanation, prediction, and delight. Journal of World Business, 41(1): 36-44.

Miller, T.L., Grimes, M.G., McMullen, J.S., \& Vogus, J.J. 2012. Venturing for others with heart and head: How compassion encourages social entrepreneurship. Academy of Management Review, 37(4): 616-640.

Mintzberg, H. 2009. Managing. Berrett-Koehler: San Francisco, CA.

Prescott, E.C., \& Visscher, M. 1980. Organizational capital. Journal of Political Economy, 88: 446-461.

Reed, R., \& DeFillippi, R.J. 1990. Causal ambiguity, barriers to imitation, and sustainable competitive advantage. Academy of Management Review, 15(1): 88-102.

Shaw, J., Duffy, M., Johnson, J., \& Lockhart, D. 2005. Turnover, social capital losses, and performance. Academy of Management Journal, 48: 594-606.

Short, J., Moss, T., \& Lumpkin, G. 2009. Research in social entrepreneurship: past contributions and future opportunities. Strategic Entrepreneurship Journal, 3(2): 161-194.

Weerawardena, J., \& Mort, G. 2006. Investigating social entrepreneurship: a multidimensional model. Journal of World Business, 41(1): 21-35. 